\title{
THE DECLINING BIRTH RATE
}

\author{
Better Classes of Population in United States Marrying more Frequently and at \\ Earlier Age than in the Past, but Number of Births Decreases - Cause \\ of Fall Mainly Psychological-Interests of Individual \\ Versus Interests of Race.
}

F. H. Hankins,

Professor of Political Economy and Statistics, Clark University, Worcester, Mass.

$\mathrm{I}^{\mathrm{T}}$ $T$ IS a self-evident fact that when death-rates begin to exceed birthrates in any race or nation it is only a matter of time until that race or nation is supplanted by another in which there is an annual increase in numbers. History shows that racial stocks with a redundant fertility have flowed out from ancestral homes to take possession of new territory. Likewise military strength and survival have been at times roughly proportional to numbers. Industrial and commercial prestige is also roughly proportional to population among nations of approximately the same stage of economic development. Differential decline in birth-rates therefore-tends to upset the comparative standing of races and nations. Moreover and most significant of all, a checked birth-rate reduces the operation of natural selection and thus tends to interfere with the process by which man increased in physical strength and intelligence.

More than a century ago Malthus declared that there was a tendency for population to increase faster than the means of subsistence. Observing the great mass of poverty and degradation in contemporary England, he was led to the belief that numbers of a population must be kept within bounds by famine, pestilence, poverty, vice, crime, and war. Malthus pointed out that the only way to obviate the operation of these positive checks was the introduction of the negative check upon population increase. By this he meant moral restraint, including thereunder both postponement of marriage and continence within the marriage relation.
A century's experience has shown that food supply and the conveniences and comforts of life can be multiplied by man's inventive and industrial capacities more rapidly than the population increases. Doubtless no period in the world's history has shown an equal increase in numbers of the white or civilized races. Nevertheless the white world's supply of consumable goods has increased several fold per capita. We are, therefore, today under the necessity of considerably modifying the Malthusian formula. There is, experience shows, no inevitable and fatalistic tendency among advanced nations for population to increase beyond bounds; but there is in every social rank a consciousness of the conflict between reproductive forces and the desires for wealth, education, recreation, leisure, social position, foreign travel, and other features of an advancing standard of living.

PRESSURE IS INTENSIFIED.

It is now well established that the pressure of population which Malthus laid so much stress upon is not a pressure upon the means of subsistence, but rather upon the standards of living. Moreover recent experience would seem to indicate that this pressure is intensified rather than reduced by an increase in wealth, so that the size of the family tends to diminish as one ascends the social scale. Malthus's error therefore was in the supposition that population would forever tend to expand with its material basis. At the very time when the thinking people of Western Europe were thrown into a most profound pessimism by his treatise, there was 
beginning in France and America an actual decline in the birth-rate. This decline did not become pronounced in Western Europe until the decade 1870 to 1880. It is more than a coincidence that at this same period Mrs. Annie Besant and her confrères in Theosophy began openly to advocate New-Malthusianism. They contended that the number of children in a family should be consciously limited. To this extent they agreed with the moral restraint doctrine of Malthus; but they did not advocate the postponement of marriage, but rather interference with the normal processes of reproduction. Since the late seventies the entire Western world has silently acquiesced in this doctrine, so that we find today that contrary to the expectation of Malthus, our world is no longer in the mysterious and inexorable grasp of nature's demand to increase, but rather man is achieving control of his own perpetuation. This control is spreading to all ranks of the population so that for the first time in history the conflict of a democratic demand for high standards of living with the forces of sex and race responsibility threatens the perpetuation of entire nations. Man's expanding knowledge gives him the true freedom which comes from a conscientious and intelligent control of his environment and his own destiny, but of all his achievements none is so momentous for the future as the control over the forces of his own generation.

\section{HERBERT SPENCER'S THEORY.}

Another very interesting historical theory of population is that set forth by Herbert Spencer in the early fifties. The main thesis which Spencer sought to demonstrate is that there is a direct and unalterable opposition between individuation or individual development and genesis. His fundamental contention was that the surplus energy of an organism has two possible uses-individual growth or activity and multiplication. He showed that as animals grow in size, and above all as their nervous systems become larger and more complex the number of their offspring becomes smaller. As the individual of a species becomes highly developed and therefore able to compete more successfully with its natural enemies, the balance of nature requires that the offspring shall diminish in number. A codfish, countless numbers of whose eggs and young will be eaten, must spawn a million eggs to produce one mature descendant, but not so with the shark, the elephant, or man. Now, without going further into Spencer's reasoning, we may see here a fundamental principle to guide us in considering the problem before us.

In the earlier stages of social evolution the possibilities of individual development were narrowly restricted by the necessities of racial subsistence and perpetuation. But as man achieved a larger and larger control over nature, as he acquired knowledge and material goods, the importance of the individual increased, until in modern societies the perfection of the individual personality has come to be the chief end of social endeavor. It is among those peoples and classes where the number of offspring is greatest that individual development is lowest. On the other hand progress in knowledge and the spread of the fruits of civilization to the lower class is everywhere accompanied by a decrease in the size of the family and an increase in individual development. But if the forces of individuation, that is the opportunities and desires for personal achievement and enjoyment, outrun the forces of genesis, that is the obligations to the race, civilization will defeat itself by producing race suicide.

There is still another generalization from Spencer of special interest in this connection. He laid down as the final criteria by which one may judge the stage of evolution of the family the following principles: the first end of the family is perpetuation of the species; the second is the welfare of the offspring; and the third the welfare of the parents. That form of family is best which fulfills in due proportion all three purposes. He therefore drew the conclusion that that form of family is highest in which the period preceding reproduction is lengthened; in which the number of offspring is reduced to the minimum consonant with the perpetuation of the species; in which the lives of parents are 
least subordinated to the rearing of offspring; in which the period following the cessation of reproduction is the longest possible; and in which finally the offspring themselves find pleasure in caring for parents in their old age.

\section{PRINCIPLES ARE APPLIED.}

These principles are in harmony with the progress of the family in recent times. There is a tendency among the upper classes to postpone marriage; the number of children is smaller, but not so small as yet, except in France, as to endanger the life of the race; a larger proportion of them are reared to maturity, they receive much greater individual-attention,. are better educated and given a better start in life; parents live longer and have a larger proportion of their lives freed from the care of children than formerly; and finally aged parents are more solicitously safeguarded than ever before. Here again we find that a decline in the birth-rate is in harmony with a higher type of family. But here also we must note that there is a conflict between some ends and others. The fundamental purpose of the family as a social institution is the perpetuation of the species; it is this which makes the family so profoundly important; it is this which accounts for the extraordinary care with which society at all stages has safeguarded it by numerous restrictions and requirements. When therefore the pleasure-seeking of parents, or their welfare in any other regard, which is the third purpose of the family, comes to dominate the racial responsibility which is its first purpose, then it is no longer in harmony with the conditions which a permanent society is bound to enforce.

Space does not permit a statement of the extent of the decline in the birthrate. It is generally known that every Western nation is experiencing a decrease in its birth-rate. It is also a matter of common knowledge that this phenomenon is disturbing the balance of power and raising questions of the greatest political and military significance.

When it comes to the causes of this decline there is less unanimity. This is one of the subjects in the explanation of which causes stated often prove merely a presentation of the personal biases of their propounders. Only the more important can be noted here.

It is commonly thought that an important factor in the decline of the birthrate is the postponement of marriage. The statisticians of a decade or more ago were accustomed to show a close correlation between the marriage rate and the birth-rate. The marriage rate varied either directly or indirectly as did economic conditions, and the births followed a similar course a year or two later. But now this connection is being seriously disturbed. In France there has been a very slight decrease in the proportion of persons under 20 who are married; 'but this has been 'more' than offset by an increase in the proportion of those of ages 20 to 30 who are married. Indeed in Europe generally the proportion of persons under 30 who are married is increasing except in England and Scotland. Moreover on the whole marriages take place earlier in France than in England, Germany, or America. Nor is this all, for a larger proportion of the French population is married than in any of these other countries. Thus the birth-rate in France has continued to fall in spite of those very conditions which should have sustained it or even caused it to increase.

\section{IN THE UNITED STATES.}

In the United States, contrary to popular opinion, marriages are not only more numerous but are contracted at earlier ages than they were 20 to 25 years ago. Thus when comparison is made of the censuses of 1890,1900 , and 1910 , it is found that the proportion of the population classed as single has steadily diminished and the proportion of married has steadily increased. Moreover this is true of both sexes. When a study is made of conjugal condition by all classes one is astonished to find that a larger proportion of young men of age groups 15-19, 20-24, and 25-34 were married in 1910 than in 1890 or 1900 ; and that a larger proportion of young women of ages 15-19 and 20-24 were married in 1910 than formerly. One is therefore forced to the conclusion that if we view the population of the United States as a whole marriage is 
neither avoided nor postponed as compared with a decade or two ago, but that on the contrary it is more general than heretofore and is undertaken at earlier ages.

If now we carry our inquiry a little farther we meet with other surprises. The census classifies the population under four headings, Native White of Native Parentage, Native White ot Foreign or Mixed Parentage, ForeignBorn White, and Negro. The returns show that in every one of these four groups there was a larger proportion of married among both sexes in 1910 than in 1890, except among Foreign-Born Whites where the proportion was practically the same (62.2 in 1890 and 62.1 in 1910). Moreover when age groups are studied, one finds that the proportion of married is greater in 1910 than in 1900 or 1890 in all four nativity classes for both males and females of ages 15-19 and 20-24; and that this is also true for both sexes and all four classes in the age group 25-34, except among foreign-born males where the proportion in 1910, though larger than in 1890 , was slightly smaller than in 1900.

We are forced therefore to conclude that in all nativity classes of the population as in the population as a whole there is a tendency for the proportion of persons married to increase and a tendency for marriages to be undertaken at an earlier age. This is a very unexpected result with respect to the native whites of native parentage. This class includes those whose parents were born in this country; it is to this class that the professional and propertied familes belong and it is frequently asserted that this class is avoiding marriage to an extent that shows a decline in their sense of social responsibility. While it is true that marriage is later in this class than among artisans and unskilled laborers, and while in certain strata of this class the age of marriage is doubtless later than formerly, nevertheless taken as a whole it is undertaking marriage as readily as, and even more readily than, in past decades.

Numerous other causes have been brought forward by the French students of this phenomenon. The style of women's dress; over-eating, especially consumption of meats; over-refinement; salacious literature, the theatre and other excitants of morbid cravings are believed by some to be causes. Then much stress is laid upon physiological sterility; but statistical evidence seems to minimize its significance. Doubtless considerable importance must be attributed to venereal infections.

\section{CAUSE IS PSYCHOLOGICAL.}

But magnify as we may all other causes of the decline, the fact remains that the one conspicuous factor is the changed psychological attitude toward the size of the family. This change in attitude has a great variety of causes. In the first place the very possibility of escaping the normal consequences of natural instincts in this regard would prompt general adoption of the means thereto. Have not various inquiries shown; and is it not self-evident fact, that women have in the past been held in the iron grasp of an inexorable fate which has imposed upon them in a large proportion of cases the complete sacrifice of themselves to a monotonous round of drudgery and child bearing? The increasing freedom of woman, the growing power and importance of her personality, the inevitable demand on her part to be recognized as an equal in the responsibilities and the honors of racial achievement; all these have reacted upon the size of the family. There has in addition been a great decline in religious control; the most Catholic department in France has had in recent years an excess of births over deaths seven times as great in proportion as the rest of the country.

Then there is the imitation of the rich by the poor, of the social élite by all others. It has been and still is true that the big families live in the little houses and the little families in the big houses; but more and more generally it is becoming true that the children who grow up in the little houses are demanding the education, the training, the leisure, the social opportunities of those who grow up in the big houses, and their parents are ambitious to give them every possible advantage. Here indeed is the great central fact,-individual ambition. 
Here is Spencer's principle of the tendency of progress to magnify and exalt the individual personality; here also is his principle that social advance is accompanied by a decreasing sacrifice of parents to racial demands.

Now this of course has its good and its bad features. There may be individual ambition which takes the direction of pure sordidness-the excessive selfishness of the woman who will not surrender a part of her inconsequential and socially valueless card playing and dancing or of the man who doesn't want to share any of his income or his property and the freedom they give him. Now it is equally true that neither matrimonial concubinage nor brutal, soul-destroying selfishness are socially justifiable. Individual ambition may on the other hand take the direction of social achievement. It is undoubtedly true that children are an impediment to the man or woman who would win fame in business, science, literature or art. But here what society loses in talented offspring is in part counterbalanced by greater present achievement. Individual ambition may and now frequently does take the direction of a desire for the better training and equipment of children for the duties of life. When, however, the combination of ambition for the child and selfishness and fear on the part of the parents results in the one-child family, it often happens that the child has lost more by the absence of brother or sister than he has gained by the increased chance of a good start in life.

\section{PROPER SIZE OF FAMILY.}

There is, I believe, nothing that promises more for the solution of problems of poverty, low wages, economic inequality and kindred social problems than the fact that parents are acquiring the power to determine in each case what their family should be, but there must be a golden mean between none and a dozen which represents the socially desirable. If three or four children for each fruitful marriage are necessary to maintain the population in a stationary state, then three, four, or five children must represent the family which society would profit by standardizing. While individuals of great genius may here and there profit by complete freedom from early struggles, it nevertheless remains true sociologically that a race which is to remain strong and progressive must develop in its youth a sense of self-reliance and a willingness to undergo hardships which cannot come when all needs from childhood to manhood are provided by the paternal pocketbook.

It is extremely difficult in practice to get the wisest proportioning of size of family and economic resources. A truly democratic system would require many children of the rich and few of the poor; this would quickly destroy class divisions. The rich, the well-to-do, the professional classes maintain their supremacy in the social system partly because their numbers are small and unskilled laborers do the meanest work at the lowest wages because their numbers are large. But a more ideal social arrangement will be that in which the number of children is so related to the economic status of the family that individual ambition will not be killed by the enervating effects of luxury on the one hand or the demoralizing effects of poverty on the other. Such an arrangement would permit most rather than the favored few to share the fruits of civilization, would so enlarge the opportunities of the lower classes that society would get the benefit of much talent at present smothered by the grime and toil of economic insecurity.

There are those conspicuous in the councils of the nation who urge upon all the public duty and the personal joys of large families. But there is reason to suppose that the unfit are now multiplying more rapidly than the fit. And in the second place the chief fault with modern society is that it has too many poor, too many at the bottom already. What we ought to work toward as a public policy is the reduction of the great mass of unskilled labor and the consequent equalization of economic opportunities. Of course there are diferent ideals of what society ought to be. Some prefer great masses of people, large volumes of imports and exports, great armies and the pomp and noise of a world power; and they prefer these things even though they be purchased 
at the expense of great inequalities, much poverty, and a low standard of public life. Others prefer a greater equalization of wealth, a juster distribution of life's opportunities, increase in the general intelligence, and achievement in civilization rather than in money making. We hear of many philanthropic measures to better the condition of the poor, but there is no proposal which will be so efficacious in the elevation of their status as the reduction of their numbers. The propaganda now being carried on by the Neo-Mathusians and the Socialists among working people, whatever may be its other social consequences, will raise the economic and social status of those whom every true democrat devoutly wishes to share in the best that life affords.

\section{A DIFFERENTIAL DECLINE.}

Another important feature of this whole problem is the probability that the decline in the birth-rate has affected the better stocks more generally than the poorer, with the result that Western nations are now reproducing themselves mainly from the less able. This would gradually shut off the supply of talented men, of geniuses, of men who invent, discover, and create, of men who set new standards and lead to the performance of new duties. This would be to add to race suicide the evils of racial decay and degeneration. By the lavish provision of homes, asylums, and charitable agencies of all sorts we make it easy for the lazy, the shiftless, the immoral, and the defective to multiply apace; and by the growth of sanitary and medical science we are preserving a larger and larger proportion of those whom nature would pronounce unfit.

When it comes to a comparison of the different economic classes there are those who hold that differences in rank are due entirely to differences of ability; then there are those who hold that natural abilities are about equally distributed among all classes. It is frequently argued that the one great misfortune of the poor is their poverty and that accident and good luck have played a leading rôle in the elevation of those who happen to be at the top. Undoubtedly there is much truth in this; social arrangements are not just; opportunities are far from equal. But in a land where opportunities have been large and moderately well distributed, achievement becomes in a rough way an index of ability, and failure for several generations marks a family as of mediocre blood. In any case the probability that talent is altogether as frequent among the lower classes as among the upper would seem to be small. The social problem with reference to the masses, even though they should be equally talented with the classes, is to so reduce their numbers and enlarge their opportunities that the inherent talent they do possess may become socially creative. At the other end of the social scale the problem is to secure a perpetuation and increase of those with natural ability.

But the statistics of college graduates indicate that a smaller proportion of them marry than some decades ago, that the age at which they marry is later, and that the number of children has fallen steadily and sharply. It surely cannot be argued that there is no social loss when families who have achieved education and economic freedom fail to maintain their places in the social composition.

On the other hand numerous studies by Eugenics Laboratory and University of London students, by Rowntree, Charles Booth, and others in America and Europe show that the lower the wages, and therefore the natural ability, the larger the family. As one ascends in the economic scale the size of the family diminishes. However much one may be impressed with the obvious inequalities of modern social arrangements and the undoubted exploitation of those rendered helpless by poverty the evidence of such facts as just cited forces the conviction that there is a tendency for advanced nations to die at the top and to be replenished too abundantly from their less able stocks.

Unless we can somehow find a way to make income proportional to inherent ability and the size of the family roughly proportional to income our civilization will neither meet the requirements of social justice nor the essential conditions of its own permanency. Just how this 


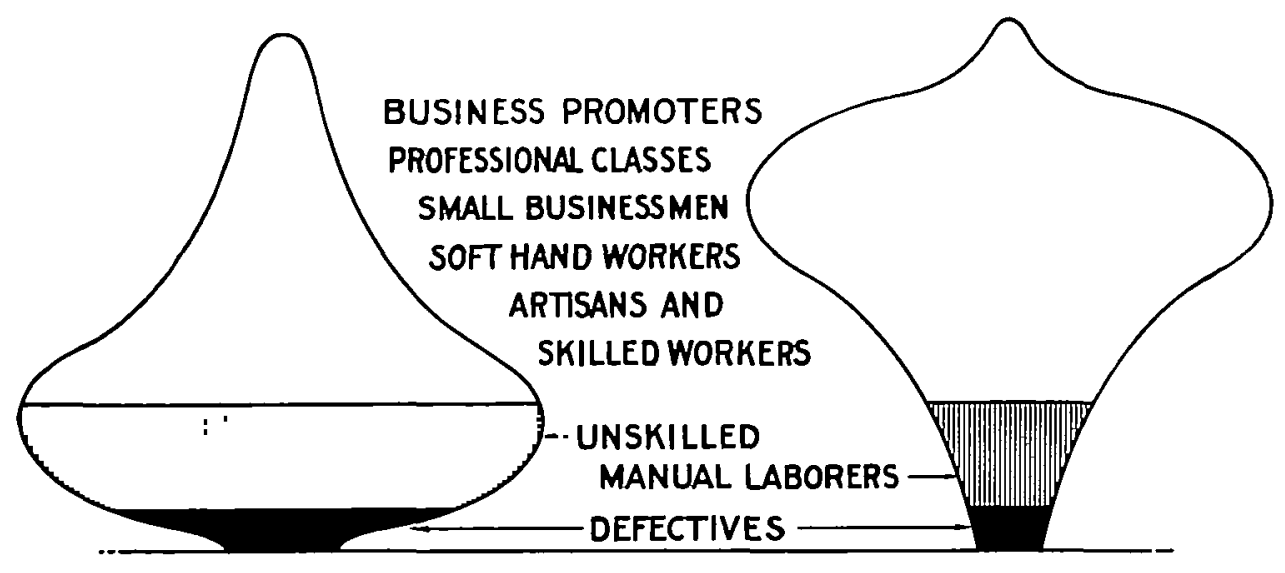

WHAT A EUGENIC REFORM WOULD MEAN

The accompanying charts show respectively the distribution of economic classes in present society (at the left) and the distribution that would result were size of family to be roughly proportional to income and native ability; were also negative eugenics to be used to prevent the multiplication of the defective; and were the educational opportunities of the industrial classes greatly increased (at the right). These charts are merely suggestive: proportions and class designations are not exact. (Fig. 18.)

is to be done is another matter. Rome's efforts to preserve her best blood by legal requirements failed. Recent French proposals include the education at public expense of every seventh child in a family; the taxation of bachelors and the exemption or abatement of taxes of fathers of large families; additional votes to fathers in proportion to the size of their families; a public bounty of 500 francs for the third and every additional child. All these and numerous other proposals lack an essential quality - they are indiscriminate and uneugenic. They would probably have the sole effect of increasing the proportion of the inefficient; they might increase numbers but they would hasten degeneration.

There are those who believe that the decline in the birth-rate cannot be checked; and it does seem that civilization tends to commit suicide by freeing the individual and enabling him to flout the race. Is it possible that a race can be kept alive only by maintaining a substratum of poverty-stricken, brutelike creatures upon whom must rest not only the weight of ceaseless toil, but the burden of renewing the ever-disappearing cultured but enervated social favorites? Can we destroy poverty, and with it the grosser injustices of our crude anarchistic social system, elevate the wholemass of the nation to sharers in the fruits of civilization and at the same time not bring self-destruction to our white blood but rather raise its quality above the best the world has yet seen? If we still wish to be optimistic we may reflect that ours is perhaps a period of transition; that man's new knowledge must ever give him added responsibility as well as increased liberty; and that there is much hope for both a finer social order and a higher type of man in the education of coming generations in what is eugenically fit and in the social responsibilities required by an altogether new and momentous power.

\section{Need of Family Histories}

The investigation of human eugenics-that is, of the conditions under which men of a high type are produced-is at present extremely hampered by want of full family histories, both medical and general, extending over three or four generations. Believing, as I do, that human eugenics, will become recognized before long as a study of the highest practical importance, it seems to me that no time ought to be lost in encouraging and directing a habit of compiling personal and family histories.-Francis Galton: Inquiries into Human Faculty (1907). 